\title{
Uma Proposta e Formação em Humanização para Medicos Residentes
}

Ribeiro, Manoel Carlos Sampaio de Almeida; Bivanco, Danielle; Moura, Juliana; Affonso, Fernanda de Carvalho; Pinto, Antonio Carlos G. S.; Cuginotti, Aloisio; Irano, Rosangela

FCMSCSP — mcrmacal@gmail.com

Introdução: a PNH tem como objetivo humanizar as práticas de saúde e de gestão em saúde em todos os níveis do Sistema Único de Saúde, em busca da valorização do usuário, dos trabalhadores, e dos gestores com gestão participativa, com objetivo de buscar a excelência no cuidado ao usuário. a PNH propõe o uso da Clínica Ampliada como forma de ampliar a compreensão do processo saúde-doença, a valorizar da dimensão subjetiva e social do adoecimento de cada indivíduo e promover um trabalho em equipe. por outro lado, a OMS recomenda que os médicos sejam treinados em competências de comunicação pois, com isso, há melhora da construção da anamnese, melhora acurácia de diagnóstico, reduzindo consumo de recursos, com maior satisfação de pacientes e dos próprios médicos. a Residência Médica é uma modalidade de formação médica realizada após o término da graduação, em hospitais credenciados, baseada no ensino e treinamento em serviço, isto é, no exercício da prática médica. Através dela, busca-se complementar a formação médica e a especialização. no entanto, muito pouca atenção tem sido dada a formação em humanização nesta etapa tão central da formação médica quer nas diretrizes e ações da $\mathrm{PNH}$, quer seja no desenvolvimento das competências de comunicação. Objetivo: Discutir as bases de um programa de formação em humanização para médico residentes Metodologia: Foi constituída uma equipe com profissionais com dois perfis: profissionais com grande experiência em desenvolvimento de ações de PNH e gestão hospitalar e professores de medicina com experiência no ensino de medicina centrada no paciente, medicina narrativa e comunicação. Através da conversa destes dois olhares se construíram os objetivos do curso de formação As estratégicas pedagógicas levaram em consideração o excesso de atividades dos residentes, a experiência e vivencias dos mesmos e uso de metodologias ativas. Resultados: o curso concebido tem como alvo o médico residente de primeiro ano, com duração de 36 horas (18 encontros de 2 horas), com os seguintes objetivos: 1. Sensibilizar médicos residentes sobre a importância e o impacto de um cuidado humanizado aos pacientes 2. Construir e aprimorar competências de comunicação de médicos residentes 3 . Instrumentalizar médicos residentes de Oncologia Clínica para utilização da clínica ampliada e o projeto terapêutico singular no cuidado aos seus usuários/ pacientes. o conteúdo se organiza a partir de três eixos temáticos: (1) Estratégias de Efetivação da Clínica Ampliada - abordagens de comunicação e Medicina Centrada no Paciente; (2) Construção de Projeto Terapêutico Singular e o Trabalho Interprofissional; (3) Valorização do trabalho do médico residente - auto-cuidado. do ponto de vista de estratégias pedagógicas, o curso utilizará aulas expositivas dialogadas, simulações de atendimento, discussão de casos e construção de narrativas (textos escritos em primeira pessoa sobre os atendimentos realizados). Conclusão: Espera-se que este curso desenvolva competências comunicacionais, mude atitudes e possibilite reflexão sobre processo de trabalho do médico residente.

Ribeiro, Manoel Carlos Sampaio de Almeida; Bivanco, Danielle; Moura, Juliana; Affonso, Fernanda de Carvalho; Pinto, Antonio Carlos G. S.; Cuginotti, Aloisio; Irano, Rosangela. Uma Proposta e Formação em Humanização para Medicos Residentes. In: Anais do Congresso Internacional de Humanidades \& Humanização em Saúde [= Blucher Medical Proceedings, num.2, vol.1]. São Paulo: Editora Blucher, 2014. ISSN 2357-7282

DOI $10.5151 /$ medpro-cihhs-10729 